\title{
Participatory varietal selection in sugarcane
}

\author{
T. Rajula Shanthy
}

Received: 12 November, 2009; Accepted: 2 March, 2010

\begin{abstract}
Participatory varietal selection (PVS) is a recent approach increasingly being used in developing countries to make the farmers choose the best suited variety for their locality. Sugarcane Breeding Institute, Coimbatore implemented this participatory approach in M.R.K. Cooperative Sugar Mills Ltd., Sethiathope, Tamil Nadu during 2002 to 2006. Participatory rural appraisal and agro-eco system analysis were done with the participation of farmers to assess the situation and identify the needs of sugarcane growers. To start with, an action plan was charted out and implemented with the participation of farmers. Subsequently adaptive trials and multilocation trials were conducted in farmers' fields and two sugarcane varieties viz., CoV 92102 and Co 86032 were identified for alkaline soils. The paper gives a concrete idea of the feasibility of conducting on - farm research in participatory mode and the success thereof.
\end{abstract}

Keywords Adaptability trial, farming communities, participatory varietal selection, sugarcane

Sugarcane is one of the major commercial crops grown in India. The crop is primarily grown for sugar; apart from its use for jaggery, ethanol and other by-products viz., bagasse for cogeneration and pulp making, fodder purpose, biocompost etc. Though sugarcane is grown throughout the country, being a tropical crop it is best suited for Southern states. In Tamil Nadu, sugarcane is grown in 1.6 lakh ha with an average production of 214.10 lakh tonnes of sugarcane. The state ranks first in productivity with $105 \mathrm{t} / \mathrm{ha}$ (Anon 2009).

For the last nine decades, research activities have been

T. Rajula Shanthy $(\square)$

Senior Scientist \& Head, Extension Section

Sugarcane Breeding Institute, Coimbatore 641007

email: rajula.sbi@gmail.com carried out at Sugarcane Breeding Institute Coimbatore to generate new production technologies, mainly genetically improved varieties. So far at least 2800 Co varieties have been released for commercial cultivation (Anon. 2008). Not all the varieties have been commercially successful. There are specific characteristics in a sugarcane variety which makes it popular. The spread and acceptance of any variety depends on the perception of the farmers about that variety (Rajulashanthy and Thiagarajan 2003).

Different kinds of extension activities have been conducted to disseminate these varieties, which mainly included verification trials, frontline demonstrations, instituteindustry interface trials and popularizations (Rajulashanthy 2009).

A questionnaire based country-wide varietal survey conducted by the author during early 2000 indicated that the number of varieties adopted is less but, when adopted, they cover quite a large area. For instance, the variety Co 86032 is widely grown in Tamil Nadu state occupying nearly $90 \%$ of the cane growing area (Nair 2008).

Witcombe et al. (1996) stated that in many developing countries, most cultivars grown by farmers are old and only a few of the released cultivars are grown widely. The reasons, among others, include inadequate exposure to new varieties, despite the occasional presence of suitable ones, or the varieties are not adequate to satisfy farmers' needs. In order to alleviate this problem, one approach that has been practiced, mainly in resource poor farming communities, is participatory varietal selection (PVS). It is well documented that PVS has shown success in identifying varieties preferred by farmers, and accelerating their dissemination and increasing cultivar diversity (Joshi and Witcombe 1996; Witcombe et al. 1996; Mulatu and Belete 2001; Mulatu and Zelleke 2002). Results 
from multilocation yield trials with Tef proved that the improved varieties yield more than the farmers' local cultivars and / or the standard controls (Tefera et al. 2001). According to Dadi (1998), lack of awareness by farmers and unavailability of seeds are the most important factors for non-adoption of improved varieties, which renders the application of PVS worthwhile.

In line with the above, the objectives of the present study were to identify farmers' variety selection criteria' to enable farmers to assess the performance of alkaline resistant sugarcane varieties of their choice and to accelerate the dissemination of farmers' choiced varieties through exchange among themselves.

\section{Farmer Research Groups}

A sensitization workshop and a series of village level meetings were organised with farmers and cane development personnel of M.R.K. Cooperative Sugar Mill during the formation of farmer research groups. Twenty three volunteer farmers from the selected villages were included. The farmers were selected based on their interest and involvement during the participatory rural appraisal exercise which was then ascertained by key informants and upon the recommendations of the cane extension personnel based on priori experience.

\section{Survey for farmers' selection criteria}

A semi-structured open ended schedule was used to collect details on the selection criteria used by farmers to evaluate a sugarcane variety with 47 and 52 farmers from N.Mangalam and Vattathur villages, respectively. Farmers listed more than 21 criteria. A criterion which was mentioned by fewer than five farmers was excluded. Focus group discussions were held with 12 randomly selected farmers from each village. Cane assistants of the concerned sections of the sugar factory and extension scientists from Sugarcane Breeding Institute (SBI) served as facilitators. Each group was encouraged to add/ delete any criteria it believed to be important but not already selected. Then the criteria were reduced to 14 through the focus group discussions, and pair-wise ranking matrix was used to rank the criteria. Pair-wise ranking is a kind of participatory rural appraisal technique, which is a structured method for ranking the selection criteria in priority order in a consensus-oriented manner. The rank assignments were determined from the number of times each selection criterion was preferred by the group (Lelo et al. 1995).

\section{Varietal evaluation by farmers}

Eight sugarcane varieties that were identified by SBI as suited for alkaline soils were taken for conducting adaptive trials in the two identified villages. To start with, sett materials were provided to the factory and few progressive farmers for raising seed nursery. The varieties were then planted in farmer's fields (maximum of four per farmer) on alkaline soils in plots each measuring 0.5 acres. Recommended agronomic practices for the location including 20\% higher seed rate were applied uniformly. Farmers evaluated the varieties right from germination count to harvest.

Research guidance was provided to farmers in conducting the adaptive trials; Answers were provided to the queries of farmers and meantime farmers explained their specific reasons for the acceptance or rejection of a variety. Frequent field visits to nearby trial farms were carried out by farmers, scientists, and extension agents of the concerned sugar factory; the purpose being to share their experiences. The yield data was recorded after 12 months at harvest. Normally, in Tamil Nadu state, farmers grow one plant crop followed by at least two ratoons. Hence, for the PVS trials also, the trend of one plant followed by two ratoon crops was taken up.

\section{Farmers' varietal selection criteria}

Table 1 gives the results of farmers' varietal selection

Table 1: Farmers' varietal selection criteria of sugarcane varieties

\begin{tabular}{|c|c|c|c|c|c|}
\hline \multirow[t]{2}{*}{ S.No. } & \multirow[t]{2}{*}{ Selection criteria } & \multicolumn{2}{|c|}{$\begin{array}{l}\text { N.Mangalam }(\mathrm{N}=47) \\
\end{array}$} & \multicolumn{2}{|c|}{ Vattathur $(\mathrm{N}=52)$} \\
\hline & & $\begin{array}{c}\text { Frequency of farmers' } \\
\text { response }\end{array}$ & $\begin{array}{l}\text { Pair-wise } \\
\text { ranking }\end{array}$ & $\begin{array}{c}\text { Frequency of farmers' } \\
\text { response }\end{array}$ & Pair-wise ranking \\
\hline 1. & Plant cane yield (t/ha) & 93.62 & 1 & 86.53 & 1 \\
\hline 2. & Germination \% & 21.27 & 12 & 15.38 & 12 \\
\hline 3. & No. of tillers per clump & 78.72 & 4 & 67.30 & 4 \\
\hline 4. & Lodging & 29.78 & 10 & 21.15 & 11 \\
\hline 5. & Intensity of flowering & 23.40 & 11 & 25.00 & 10 \\
\hline 6. & Easiness in removing leaf sheath & 59.57 & 8 & 50.00 & 7 \\
\hline 7. & Using plant tops as cattle feed & 65.95 & 6 & 53.84 & 6 \\
\hline 8. & Tolerance to drought & 57.44 & 9 & 55.77 & 5 \\
\hline 9. & Tolerance to problem soils & 80.85 & 3 & 69.23 & 3 \\
\hline 10. & Tolerance to pests & 63.82 & 7 & 401.38 & 8 \\
\hline 11. & Tolerance to diseases & 61.70 & 5 & 36.53 & 9 \\
\hline 12. & Jaggery yield & 17.02 & 13 & 7.69 & 14 \\
\hline 13. & Jaggery quality & 14.89 & 14 & 9.61 & 13 \\
\hline 14. & Ratoon performance & 89.36 & 2 & 82.69 & 2 \\
\hline
\end{tabular}


criteria. More than $80 \%$ of the farmers in the study area have ranked cane yield and ratoon yield as the foremost criteria in evaluating a sugarcane variety. The cane growers are paid by the sugar factories based on tonnage irrespective of all the other cane characteristics. This would have been probably the reason for farmers to rate cane yield as the foremost criteria. During the focus group discussions as well, farmers opined that all other selection criteria are considered only if the variety is a high yielder than the existing cultivars. The other major criteria included tolerance to problem soils, number of tillers per clump and utility of plant tops as cattle feed. Farmers were less interested in other agronomic trials. Since majority of the sample farmers were registered growers of sugar factories, their less concern of jaggery yield and quality is justified. However, the ranking pattern varied to a lesser extent in the two study villages.

Farmers in the study area detrash the dried and partially dried sugarcane leaves once during $5^{\text {th }}$ month, though the recommendation is to detrash during $5^{\text {th }}$ and $7^{\text {th }}$ months. The varieties that are self-stripping and do not have spines on the leaves are preferred. Detrashing is an activity done exclusively by farm women and drudgery is more when it is difficult to remove leaf sheath and has minute spines on the lamina.

When farmers' selection criteria are strongly influenced by market demand, there is a high consistency of the criteria over years, locations and gender (Kitch et al. 1998). In the case of sugarcane, cane yield and juice quality are inversely correlated. Therefore the cane breeders strike a balance between cane yield and sucrose $\%$ so that the sugar factories and the cane growers together stand benefitted.

\section{Participatory varietal selection}

Most PVS methods follow four phases; an assessment of farmers' cultivar needs (through participatory rural appraisal or survey), a search for suitable cultivars, evaluation and selection by farmers, and dissemination of farmers' preferred cultivars (Wincombe et al. 1996).

\section{On farm adaptive trials}

In the present on-farm adaptive trials, we put all the available alkaline resistant varieties for the farmers to choose based on their performance. Searching for matching varieties with farmers' selection criteria may save time and reduce cost, but success has not always been high (Mulatu and Zelleke 2002).

The performance of sugarcane varieties in adaptive trials conducted during 2003-04 crop season (Table 2) indicated that the variety CoV 94012 performed well in both the villages with an average cane yield of $120.32 \mathrm{t} / \mathrm{ha}$ in N. Mangalam village and 115.05 t/ha in Vattathur village. The variety Co 86032 gave a cane yield of $101.42 \mathrm{t} / \mathrm{ha}$ in N. Mangalam village and $98.28 \mathrm{t} /$ ha in Vattathur village. The other six varieties gave a cane yield of less than $100 \mathrm{t} / \mathrm{ha}$, the range being 55.55 to $86.67 \mathrm{t} / \mathrm{ha}$.

Table 2. Performance in adaptive trials during 2003-04 season

\begin{tabular}{lcc}
\hline \multirow{2}{*}{ Variety } & \multicolumn{2}{c}{ Yield (t/ha) } \\
\cline { 2 - 3 } & N.Mangalam & Vattathur \\
\hline Co 86032 & 101.42 & 98.28 \\
CoV 92102 & 120.32 & 115.05 \\
CoV 94101 & 86.67 & 85.83 \\
CoC 90063 & 69.93 & 55.55 \\
CoC 671 & 86.09 & 81.25 \\
Co 97009 & 77.49 & 80.00 \\
CoC 98061 & 62.50 & 75.00 \\
CoSi 96071 & 70.00 & 75.00 \\
\hline
\end{tabular}

\section{Multilocation trials}

Due to the better performance of the varieties CoV 92102 and Co 86032 were considered for further trials. Multi-location trials were laid in the alkaline patches in 20 locations of the two villages during the next cropping season to observe the sustainability of their performance.

Table 3: Performance in multilocation trials Village: N. Mangalam

\begin{tabular}{lccc}
\hline \multirow{2}{*}{ Variety } & \multicolumn{3}{c}{ Yield (t/ha) } \\
\cline { 2 - 4 } & Plant & Ratoon & Average \\
\hline Co 86032 & 77.5 & 65.0 & 71.25 \\
CoV 92102 & 80.0 & 67.5 & 73.75 \\
\hline
\end{tabular}

Village : Vattathur

\begin{tabular}{lccc}
\hline \multirow{2}{*}{ Variety } & \multicolumn{3}{c}{ Yield (t/ha) } \\
\cline { 2 - 4 } & Plant & Ratoon & Average \\
\hline Co 86032 & 82.5 & 77.5 & 80.0 \\
CoV 92102 & 85.0 & 80.0 & 82.5 \\
\hline
\end{tabular}

Table 4: Maximum yield obtained in the variety CoV 92102

\begin{tabular}{lcc}
\hline & Plant/Ratoon & Yield (t/ha) \\
\hline Plant & 202.5 \\
I Ratoon & 162.5 \\
II Ratoon & 152.5 \\
\hline
\end{tabular}

The data indicated that the variety CoV 92102 performed well in N.Mangalam (73.75 t/ha) and in Vattathur (82.5 t/ha) villages both in plant and ratoon crops. The yields were slightly lower when compared to previous season due to inadequate irrigation facility and other agro-climatic factors. Among the 20 multilocation trials, the variety $\mathrm{CoV} 92102$ gave the highest cane yield of $202.5 \mathrm{t} /$ ha in plant crop, $162.5 \mathrm{t} /$ ha in I ratoon and $152.5 \mathrm{t} /$ ha in II ratoon.

Visualizing a better performance by the variety $\mathrm{CoV} 92102$, the variety was popularized in almost $24 \%$ of the reserved area during 2005-06 and in 20\% area during 2006-07 planting season in alkaline soils to sustain the yield and recovery. The average 
yield of the factory has increased from $52 \mathrm{t} /$ ha during 2000-01 to $67.15 \mathrm{t} /$ ha during 2006-07 and the yield is sustained in the factory area.

Crop varieties must be adaptable over diverse farm environment if they are to be accepted by farmers within a region. The adoption of new techniques has been slow in diverse, less productive, heterogeneous and risk prone areas (Dambo and Sajica 1985; Chambers and Jiggins 1986). Difference in performance of varieties between recommended and farmer management practices have highlighted the importance of the choice of crop management for Variety Adaptability Trials conducted in farmers' fields. However, the interaction of management practices with genotype is not always recommended in plant breeding and selection (Hammer et al. 1996). Ceccarelli (1996) evaluated breeding material in farmers' fields by letting farmers manage the crop and concluded that the evaluation was successful.

The results are in agreement with other PVS studies, which have shown that, above a certain minimum yield, the acceptability of a variety is determined by factors other than yield (Kitch et al. 1998). Generally, it appears that participatory varietal selection in sugarcane is best suited for choosing an appropriate variety to the prevailing climatic factors and soil conditions apart from other associated biotic stresses.

\section{References}

Anonymons (2007-08) Annual report. Sugarcane Breeding Institute, Coimbatore.

Anonymons (2009) Sugar Statistics. Cooperative Sugar. 40(8):72-73

Ceccarelli S (1996) Positive interpretation of genotype by environment interaction in relation to sustainability and biodiversity. In Plant Adaptation and Crop Improvement (Eds M. Cooper and G.I. Hammer). Cambridge University Press. 467-486.
Chambers R, Jiggins J (1986) Agricultural research for resource poor farmers - a parsimonious paradigm division. P. 220. Institute of Development Studies, University of Sussex, Brighton, UK .38

Dadi I (1998) Adoption and diffusion of agricultural technologies: Case of East and West Shervazones Ethopia. Ph.D Thesis, University of Manchester, UK.

Dambo AT, Sajica PE (1985) Developing a regional network for interdisciplinary research on rural ecology in the south east Asian universities. Agro-eco system network experience. Te Experimental Agriculture. 7: 289-298.

Joshi A, Witcombe JR (1996) Farmer participatory crop improvement 2. Participatory varietal selection - A case study in India. Experimental Agriculture 32: 461 - 477.

Hammer GI, Butler DG, Buuchow RG, Monica H (1996) Integarting physiological understanding and plant breeding via crop modeling and optimization. In Plant adaptation and plant breeding via crop modeling and optimization. In Plant adaptation and crop improvement 419-441. (Ed. R.Cooper and G.I Hariwar, Cambridge Univ. Press).

Kitch LW, Boukar O, Endondo C, Murdock LL (1998). Farmer acceptability criteria in breeding cowpea. Experimental Agriculture 34: 475-486.

Lelo E, Ayieko J, Muhia P, Njeremani D, Muiriri H, Omello J, Ochelo W (1995) Field handbook for participatory rural appraisal practitioners. The PCA programme. Egerton University, Kenya.

Mullatu E, Belete K (2001) Participatory variety selection in lowland sorghum in Eastern Ethiopia - Impact on adoption and genetic diversity. Experimental Agriculture. 37: 211-229.

Mullatu E, Zelleke H (2002) Farmers' highland maize selection criteria: Implications for maize breeding for the Hararghe highlands of eastern Ethiopia. Euphytica 127: 11-30

Nair NV (2008) Sugaracne Breeding Institute - A perspective. SugarTech 10(4):285-292.

Rajulashanthy T, Thiagarajan R (2003) Perception of farmers about the varieties. Cooperative Sugar 34(7) : 563-567.

Tefera H, Assefa K, Hundera F, Kefyalew T, Teklu Y, Gugsa L, Ketema $\mathrm{S}$, Adnew T (2001) Progress in tef breeding research in Ethiopia. In Narrowing the rift: Tef research and development. 157-164 (Eds. H. Tefera, G. Belay and M. Sorrels)\{. Addid Ababa: Ethiopia.

Witcombe JR, Joshi A, Joshi KD, Stahpit BR (1996) Farmer participatory crop improvement. I. Varietal selection and breeding methods and their impact on biodiversity. Experimental Agriculture 32: 445460 . 